\title{
Preservation of singing in Broca's aphasia
}

\author{
A. YAMADORI, Y. OSUMI, S. MASUHARA, A N D . OKUBO \\ From Kobe University School of Medicine, Department of Neurology and Psychiatry and Tamatsu \\ Rehabilitation Center Hospital, Section of Speech Therapy, Kobe, Japan
}

SUMMARY Twenty-four right-handed, right hemiparetic patients with Broca's aphasia were examined for their singing capacity. Twenty-one $(87.5 \%)$ produced good melody. Twelve of these $(57 \%)$ produced good text words while singing. It is speculated that the right hemisphere is dominant over the left for singing capacity. The relationship between melodic and text singing was also discussed.

Preservation of the ability to sing in the presence of severe expressive aphasia has been known for more than a century since Béhir (1836) described a patient who was able to sing la Marseillaise or la Parisienne, while his speech was limited to 'tan', 'tan'. Edgren (1895) also cites subsequent reports by Trousseau (1865), Falret (1867), and Jackson (1871) and the fact became well established by the turn of this century. On the other hand, inability to sing (vocal motor amusia) was also observed to accompany aphasia. For example, Edgren (1895) collected 17 cases from the literature of aphasia with what he considered as vocal motor amusia. Henschen (1925) also collected many such cases and concluded that a left frontal lesion was responsible for motor amusia. These seemingly contradictory data were further complicated after L. Mann's observation (1898) that motor amusia developed after right cortical excision in a righthanded man. The presence of right hemispheric motor amusia has since been confirmed by many authors (Mendel, 1916; Mann, 1917; Jossmann, 1927; Kleist, 1934; Botez and Wertheim, 1959).

Two recent papers shed new light on the problem. Smith (1966) observed preservation of the singing faculty in a left hemispherectomised patient. Gordon and Bogen (1974) found markedly deficient singing after right carotid injection of sodium amylobarbitone, whereas speech remained relatively intact. By contrast, singing was less disturbed than speech after left carotid injection.

These facts prompted us to make a systematic study of singing ability in patients with Broca's aphasia and a critical review of the old literature on amusia.

Address for correspondence: Dr Atsushi Yamadori, Department of Neurology and Psychiatry, Kobe University School of Medicine, 7-chome, Kusunokicho, Ikutaku, Kobe, Japan, 650.

Accepted 18'Ostober 1976

\section{Method}

\section{SUBJECTS}

In order to make our group as homogeneous as possible, only those patients who showed Broca type of aphasia, who had right hemiparesis, were right handed, and had no clinical signs of right hemisphere involvement were selected. Thus, as far as clinical signs are concerned, their major lesion was supposed to be in the pre-Rolandic left cerebral hemisphere.

We studied 24 patients of ages ranging from 21 to 74 years with a mean age of 48.7 years. Fifteen were males and nine were females. The aetiology included 23 cerebrovascular diseases and one head trauma. The degree of disturbance of speech expression was divided into severe (11 cases), moderate (12), and mild (one). All subjects used to sing before the illness

\section{TECHNIQUES}

Only the capacity to sing was tested. The patient was given the titles of several popular school or folk songs and was asked if he knew one of them. If he answered in the affirmative, he was asked to sing it. If he could not do so, the first portion of the melody was given by the examiner. If this failed also, the whole melody was given. He was encouraged to hum the melody when text singing was difficult or interfered with melody production. The whole session was tape recorded and analysed later.

\section{Results}

ABILITY TO SING

All subjects tested used to sing only occasionally. No professional musicians or highly musical people were present in the group. Only one repre- 
sentative song was analysed for each subject. As shown in Table 1, 21 subjects sang satisfactorily $(87.5 \%)$. Six of them sang excellently. Two produced poor melody. One was not able to form a melody at all.

Table 1 Singing ability of 24 patients with Broca's aphasia

\begin{tabular}{lr}
\hline Singing & (no.) \\
\hline Possible & 21 \\
Poor & 2 \\
Impossible & 1 \\
Total & 24 \\
\hline
\end{tabular}

\section{ABILITY TO SING WITH TEXT WORDS}

Although 21 out of 24 patients sang fairly well, six of them were not able to produce words with melody. They only hummed the melody. Three patients produced words but literal paraphasia was noted. For example, case TS showed one syllabic confusion in singing a popular song lasting for 40 seconds. Also case ST produced one paraphasia in singing a folk song and case FT failed once in singing the national anthem. Although the number of syllabic confusions was strikingly few, these three were classified as paraphasic.

Correct and fluent text words accompanied good melody in 12 subjects, in striking contrast with their hesitant and sometimes anarthric speech (Table 2).

Table 2 Ability to sing with text words

\begin{tabular}{lc}
\hline Good melody & (no.) \\
\hline With fluent text & 12 \\
With syllabic errors & 3 \\
With no text & 6 \\
Total & 21 \\
\hline
\end{tabular}

\section{ABILITY TO SING SPONTANEOUSLY}

The necessity for cueing for initiation of singing was analysed in the 21 good singers. Five started singing without any help when the name of a song was presented. A lead of the first few notes given by the examiner was necessary for starting in eight subjects. Once started, they were able to finish their singing without further help.

For the remaining eight subjects, more than one cueing was necessary to complete their singing. Thus, three subjects required two promptings (one for the start and another in the middle). Two required three promptings and three required help to start each line. When cueing was given, the correct melody followed in all of them (Table 3 ).
Table 3 Necessity of prompting in melodic realisation

\begin{tabular}{lc}
\hline Prompting & $($ no. $)$ \\
\hline Not necessary & 5 \\
Once & 8 \\
Twice & 3 \\
Three times & 2 \\
More than three & 3 \\
Total & 21 \\
\hline
\end{tabular}

RELATIONS BETWEEN DIFFICULTY OF EXPRESSIVE SPEECH AND DIFFICULTY OF MELODIC REALISATION Of 21 good singers, the frequency of prompting necessary to complete a song was chosen as a parameter of difficulty of melodic realisation. As shown in Table 4, no clear correlation between difficulty of speech expression and difficulty of melodic realisation was found.

Table 4 Relation between difficulty of expressive speech and difficulty of melodic realisation

\begin{tabular}{llll}
\hline Degree of Broca's dysphasia & \multicolumn{3}{l}{ Number of promptings } \\
\cline { 2 - 4 } & 0 & 1 & $2+$ \\
\hline Severe & 2 & 4 & 5 \\
Moderate & 2 & 4 & 2 \\
Mild & 3 & 0 & 1 \\
\hline
\end{tabular}

There seems to be a certain tendency for severe aphasics to need more promptings, but two of the severe Broca's group could sing well without any promptings, while the only subject who belonged to the mild Broca's group required more than two promptings to complete singing.

RELATION BETWEEN DIFFICULTY OF EXPRESSIVE SPEECH AND DIFFICULTY OF TEXT WORD REALISATION Degree of difficulty of text word singing in 21 good singers was classified into three groups as shown above; no error, paraphasic, and no word group. There was no clear correlation observed between difficulty in text word production and difficulty of expressive speech (Table 5). Of 11 severe Broca's aphasics, five produced good text words without any errors while singing. Although in the moderate group there was a certain tendency to produce a text word more easily than the severe group, this was by no means conclusive.

Table 5 Relation between difficulty of expressive speech and difficulty of text word singing

\begin{tabular}{llll}
\hline Degree of Broca's dysphasia & \multicolumn{3}{l}{ Text singing } \\
\cline { 2 - 4 } & Fluent & Paraphasic & None \\
\hline Severe & 5 & 1 & 5 \\
Moderate & 6 & 2 & 1 \\
Mild & 1 & 0 & 0 \\
\hline
\end{tabular}


RELATION BETWEEN MELODIC REALISATION AND TEXT WORD PRODUCTION

Finally, from 21 good singers, six excellent performers were chosen and the relation between their singing ability and fluency of text word production was examined. Again no correlation was found. For example, case TF who could produce only a couple of stereotyped interjections in spontaneous speech, hummed 'Auld Lang Syne' very well but was not able to produce a single text word. On the other hand, case TO who could say only her name and a few greetings, sang 'Do Re Mi' excellently with fluent words.

Table 6 Relation between melodic realisation and text production: six excellent singers

\begin{tabular}{llllll}
\hline Case & Sex & $\begin{array}{c}\text { Age } \\
(y r)\end{array}$ & $\begin{array}{l}\text { Severity of } \\
\text { aphasia }\end{array}$ & $\begin{array}{l}\text { Text sung } \\
\text { or not }\end{array}$ & $\begin{array}{l}\text { Prompting } \\
\text { necessary } \\
\text { or not }\end{array}$ \\
\hline TI & M & 28 & Moderate & No & No \\
TO & F & 21 & Severe & Yes & No \\
SK & F & 38 & Moderate & Yes & No \\
TT & M & 41 & Moderate & Yes & Yes \\
FN & M & 61 & Moderate & Yes & Yes \\
TF & M & 51 & Severe & No & Yes \\
\hline
\end{tabular}

\section{Discussion}

Of the 24 right-handed, right hemiparetic patients with Broca's aphasia, the capacity to sing in some degree was preserved in 21 . This high proportion of preservation of melodic capacity in the presence of expressive speech difficulty suggests that the melodic faculty is somewhat independent from that of speech.

There are three possible explanations: (1) a still intact part of the left hemisphere controls singing; (2) the right hemisphere is dominant for singing;

(3) the subcortical structure is responsible.

We have reviewed the literature on the capacity for musical expression and are inclined to support the second hypothesis.

The history of observation on the preservation of singing in otherwise speechless patients is almost as long as the history of aphasia. According to Edgren (1895) the earliest known report is by Falret who in 1867 reported an anarthric patient who could still sing. In 1895 Edgren collected as many as 52 cases concerning musical faculty. Based on the correlation between aphasia and amusia, he divided the group into three; (1) 24 cases of aphasia without amusia, (2) 23 cases of aphasia with amusia, and (3) five cases of amusia without aphasia. Although his discussion extended to both motor and sensory aspects of musical capacity, we would like to limit our attention to the singing faculty only. He concluded briefly that the lesion responsible for motor amusia seemed to lie in the left frontal area closely related to that of aphasia but not necessarily identical. This view later became the accepted one, but a closer look at his data led us to a different conclusion. Of his aphasia without amusia group, there were 14 cases who showed Broca's aphasia as well as right hemiplegia. Of these 14 cases, three could sing with text words and 11 hummed the melody without words. As for prompting, two required no prompting and nine required some kind of cueing. For the other three cases there was no mention on this point. In the aphasia with amusia group, 16 right hemiparetic patients with Broca's aphasia were included. It is interesting to note that of these 16 cases, six could be considered as having preserved singing capacity because they were described as having sung well when prompted. Three more could even sing without any cueing. Thus, in our opinion, only seven of this group can properly be called vocally amusic. To summarise. 30 of the cases collected by Edgren were of Broca's aphasia with right hemiparesis. Of these as many as 23 cases preserved singing capacity to a certain degree $(76.7 \%$ ). Only seven lost singing ability. The percentage is close to that of our own figure of $87.5 \%$.

Preservation of singing was not a focus of interest again until Smith (1966) reported a left hemispherectomised patient who could still sing. The high proportion of preservation of singing in expressive aphasia as well as the preserved singing capacity in a patient with no left hemisphere, tend to suggest that the singing faculty resides in the right hemisphere.

Another line of approach to this problem comes from the observation of amusia. Three years after Edgren, L. Mann (1898) reported a curious case. A right-handed man suffered from a head trauma. Ten months later, because of left arm Jacksonian seizures, two successive right frontal cortical excisions were performed. Loss of singing and whistling followed. He used to be a good singer. No aphasia was observed. At necropsy, a cyst (4.5 $\mathrm{cm}$ in length and $2.5 \mathrm{~cm}$ in depth) was found in the posterior half of the middle frontal gyrus of the right hemisphere.

In 1917, M. Mann reported another case. A right-handed patient lost the faculty of singing after a right parietal shrapnel wound. The patient did not lose the faculty of speech. Jossmann (1927) reported a case who developed vocal motor amusia after resection of the right carotid artery.

Kleist (1934) thought that vocal motor amusia could result from either hemisphere. Yet his left 
hemisphere case is not very persuasive. The patient could sing well when prompted. On the other hand, his right hemisphere case is very interesting. A right-hander with a right-frontoparietal shrapnel wound developed vocal motor amusia. His singing became very faulty. When the right frontal scar tissue was frozen by ethyl chloride even this faulty degree of singing capacity disappeared. The scar was at the lower end of the right middle frontal gyrus $(6 \mathrm{~cm}$ in length and $4 \mathrm{~cm}$ in width). Botez and Wertheim (1959) reported a patient with a right frontal oligodendroglioma who became amusic expressively after operation.

The literature of this kind is far from abundant, but the published cases of right hemisphere vocal amusia are all very clear and leave no doubt that they are amusic, while left hemispheric cases are sometimes not very persuasive and, as mentioned, some do not seem to be very amusic. In this respect the recent report by Gordon and Bogen (1974) of the intracarotid injection of sodium amylobarbitone strongly supports the right hemisphere hypothesis. They found that, after right carotid injection, singing became markedly deficient, whereas speech remained relatively intact. By contrast, singing was less disturbed than speech after left carotid injection of the drug.

Thus, it could be speculated that, as far as melodic production is concerned, the right hemisphere is more responsible than the left. But the degree of dominance does not seem to be as high as that of speech realisation.

The fact that 16 out of 21 cases $(76.2 \%)$ required some kind of prompting to initiate or to continue singing may mean that the ability to initiate singing spontaneously is more related to the left hemisphere than to the right.

Relationship between melodic realisation and text word production is not clear at present. Our data suggest that they may be indepedent of each other. Good melodic realisation did not necessarily lead to good text word production. Further, severity of speech realisation did not go in parallel with severity of text word production. These aspects remain to be explored.

\section{References}

Béhir, M. (1836) cited by Edgren (1895).

Botez, M. I., and Wertheim, N. (1959). Expressive aphasia and amusia. Brain, 82, 186-201.

Edgren, J. G. (1895). Amusie (musikalische Aphasie). Deutsche Zeitschrift für Nervenheilkunde, 6, 1-64.

Falret (1867). Aphasie. Dictionnaire Encyclopédique des Sciences Médicales, 5, 620. (Cited by Edgren, 1895.)

Gordon, H. W., and Bogen, J. E. (1974). Hemispheric lateralization of singing after intracarotid sodium amylobarbitone. Journal of Neurology, Neurosurgery, and Psychiatry, 37, 727-738.

Henschen, S. E. (1925). Clinical and anatomical contributions on brain pathology. Archives of Neurology and Psychiatry (Chic.), 13, 226-249.

Jackson, H. (1871). Lancet, 2, 430-431. (Title unknown; cited by Edgren, 1895.)

Jossmann, P. (1927). Die Beziehungen der motorischenAmusie zu den apraktischen Störungen. Monatschrif $t$ 的 für Psychiatrie und Neurologie, 63, 239-274.

Kleist, K. (1934). Gehirnpathologie, Barth: Leipzig.

Mann, L. (1898). Casuistische Beiträge zur Hirnchirurgie und Hirnlocalization. Monatschrift für Psychiatrie und Neurologie, 4, 369-378.

Mann, M. (1917). Ein Fall von motorischer Amusie Neurologische Centralblatt, 36, 149-151.

Mendel, K. (1916). Kriegbeobachtungen. I. Motorische Amusie. Zeitschrift für die gesamte Neurologie und Psychiatrie, 8, 169.

Smith, A. (1966). Speech and other functions after left hemispherectomy. Journal of Neurology, Neurosurgery', and Psychiatry, 29, 467-471.

Trousseau, A. (1865). Clinique Médicale, 2, 622. (Title unknown; cited by Edgren, 1895.) 